\author{
Asian Journal of Economic Modelling \\ $\operatorname{ISSN}(e): \quad 2312-3656$ \\ $\operatorname{ISSN}(p): \quad 2313-2884$ \\ DOI: $10.18488 /$ journal.8.2014.24.156.168 \\ Vol. 2, No. 4, 156-168 \\ (C) 2014 AESS Publications. All Rights Reserved. \\ URL: wrw.aessweb.com
}

\title{
LINKING UNEMPLOYMENT TO INFLATION AND ECONOMIC GROWTH: TOWARD A BETTER UNDERSTANDING OF UNEMPLOYMENT IN THE PHILIPPINES
}

\section{Pamela F. Resurreccion}

\author{
Associate Professor V, Department of Marketing, MSU - Iligan Institute of \\ Technology of Iligan City, Philippines.
}

Keywords
Okun's law
Phillips's curve
Unemployment
Inflation
Economic growth
Ordinary least squares regression
Philippines.

Philippines.

\begin{abstract}
Unemployment is among the major problems not only in less developed and developing countries but in developed countries as well. It spells out the extent of poverty a household will have to sustain. Strongly influenced by the premises of the Okun's Law and Phillips Curve, this study sought to determine the link between unemployment and inflation and economic growth. An additional explanatory variable, age dependency ratio, was introduced to investigate this facet of unemployment which is based on the premise that a high age dependency ratio would result to lower unemployment. Unit root tests were employed to the data series prior to testing the hypothesized relationships which employed ordinary least squares (OLS) regression technique. Tests for heteroskedasticity and collinearity were done using White's test and VIF, respectively. It was found that unemployment is negatively related to inflation and economic growth, confirming Okun's Law and Philips Curve in the Philippines for the period covering 1980 to 2009. Moreover, age dependency ratio was found to be positively related with unemployment albeit, the relationship is not significant. The coefficient of determination obtained for the model was $72.7 \%$ hence overall, the regression line relatively describes the data well.
\end{abstract}

Contribution/ Originality: This study contributes to the existing literature on the link between unemployment, inflation, and economic growth in the Philippine context. Furthermore, the study introduces age dependency ratio as an explanatory variable based on the premise that a high age dependency ratio would result to lower unemployment.

\section{INTRODUCTION}

Unemployment is among the major problems not only in less developed and developing countries but in developed countries as well. Unemployment is the condition of having no job or 
being out of work or proportion of people which are able to work and actively searching jobs but they are unable to find it. (Rafiq et al., 2010). The ILO (2011) defines the unemployed population as made up of persons above a specified age who are available to, but did not, furnish the supply of labor for the production of goods and services. When measured for a short reference period, it relates to all persons not in employment who would have accepted a suitable job or started an enterprise during the reference period if the opportunity arose, and who had actively looked for ways to obtain a job or start an enterprise in the near past. The impact of unemployment cannot be overemphasized enough. It spells out the extent of poverty a household will have to sustain. Considering that employment is a multiplier with a coefficient of five reflecting the average family size, one unemployed equals five starving (De La Paz, 2009). Alongside this relationship, unemployment generally decreases the household income that fuels most of their equally important living expenditures like utilities, education, and medicine.

Hence, unemployment has received much attention among economic analysts, governments, and scholars in pursuit of better understanding such occurrence and henceforth be better able to harness the forces that breeds it. This study is a contribution to the growing literature aimed at understanding the relationship between unemployment, inflation, and economic growth rate using Philippine data with a more extended and updated period of study (1961 to 2009). The relationships established herein may serve as a guide in both fiscal and monetary policy. The objectives of this paper are (a) to determine if the Philippines support Okun's Law; (b) to examine if Philippine employment and inflation data is aligned with the Phillips Curve; (c) to investigate which among inflation and economic growth rate are stronger predictors of unemployment; and (d) to test if inflation and economic growth rate are together good predictors of unemployment.

\section{LITERATURE REVIEW}

The inverse relationship between the growth rate of an economy and unemployment is a widely accepted theory in economics. This has been postulated and articulated and is well known as Okun's Law, particularly the different version of the law.

In the difference version of Okun's Law, the changes in the unemployment rate from one quarter to the next moved with quarterly growth in real output and took the form:

Change in the unemployment rate $=a+b^{*}$ (Real output growth)

This captures how output growth varies simultaneously with changes in the unemployment rate. The parameter b is often called "Okun's coefficient”(Knotek, 2007). As Knotek (2007) further explained, "one would expect the Okun's coefficient to be negative, so that rapid output growth is associated with a falling unemployment rate, and slow or negative output growth is associated with a rising unemployment rate. The ratio “-a/b" gives the rate of output growth consistent with a stable unemployment rate, or how quickly the economy would typically need to grow to maintain a given level of unemployment. Many studies have been conducted to investigate the prevalence and applicability of Okun's Law. When the movement of unemployment rate and the long and short term relationships between unemployment rate and economic growth rate are examined for individuals and pooled cases in European countries over the period 1977-2008, some evidence are found for unemployment hysteresis in all European Countries. Estimation of the 
Okun's coefficients shows that the validity of Okun's Law and the significance of the relationship between economic growth rate and unemployment rate vary between countries (Tatoglu, 2011). In a study on Jordanian data from 2000 - 2008, tests of co-integration revealed long-run association between unemployment and economic growth. On the other hand, the results support that unemployment and output is unrelated suggesting that Okun's law is not valid for Jordan (Kreishan, 2010). "Industrialized nations with labor markets that are less flexible than those of the United States, such as France and Germany, tend to have higher Okun coefficients. In those countries, the same percentage change in GNP has a smaller effect on the unemployment rate than it does in the United States"(Investopedia, 2011). Employment in the Philippines grew by nearly 40 percent from 1995 to 2009, and the pace of growth has been faster than other ASEAN-4 economies with the exception of Malaysia. Employment growth has not, however, been strong enough to reduce the unemployment rate substantially, partly due to the rapid increase in the labor force. The unemployment rate has been around 7-8 percent in recent years and remains high in comparison with other ASEAN economies (Ide et al., 2011). The IMF (2009) report further articulated that "the relationship between output growth and the unemployment rate appears relatively weak in the Philippines. Okun's law captures the relationship between these two variables, and the correlation has been historically weaker in the Philippines than in Malaysia or Thailand. The weak relationship suggests that there may be some structural issues in the Philippine labor market. One such issue could be the high proportion of self-employed workers and unpaid family workers, who account for around 40 percent of total employment. In addition, redundancy costs in the Philippines are relatively high, and hiring and firing practices are relatively heavily regulated (World Economic Forum, Global Competitiveness Report 2010-11). In this context, promoting labor market flexibility would be helpful to improve labor market efficiency. In addition, according to the Asian Development Bank, "active labor market measures such as job training and search assistance, remedial education, and job creation targeted at helping younger people may be helpful to reduce mismatches in the labor market as well as to increase employment and raise its quality (International Monetary Fund, 2011)." This weak relationship persists in the Philippines even if data is extended from 1961-1962 to 2008-2009 (Figure 1).

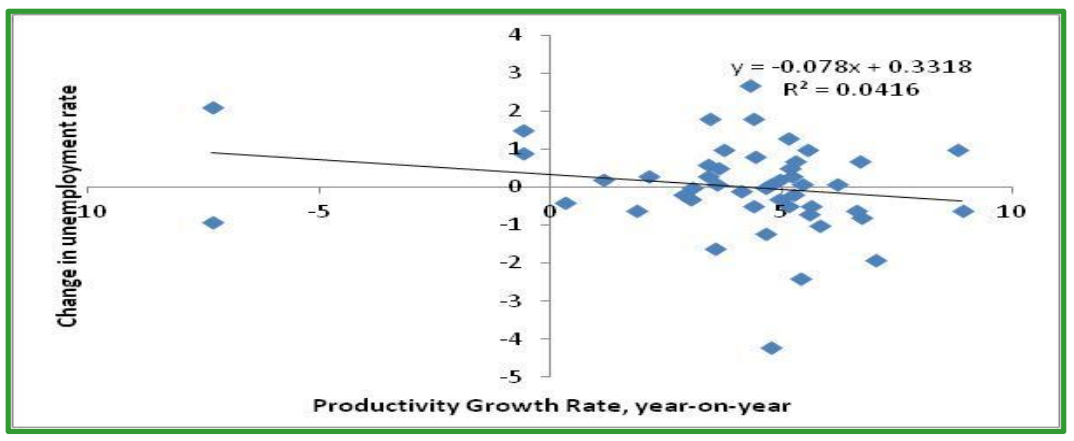

Figure-1. Okun's Law in the Philippines (Based on GDP). 
Still with reference to Okun's Law, Bautista (2003) further pointed out that the rising GDP growth rates in 1973-1975, 1992-1994, and 1998-1999 were accompanied by declining unemployment rates, while declining growth rates went hand in hand with higher unemployment rates in the downswing or crisis years of 1963-1964, 1967-1969, the early 1980s, 1997, 1999, and 2000 (See Figure 2).

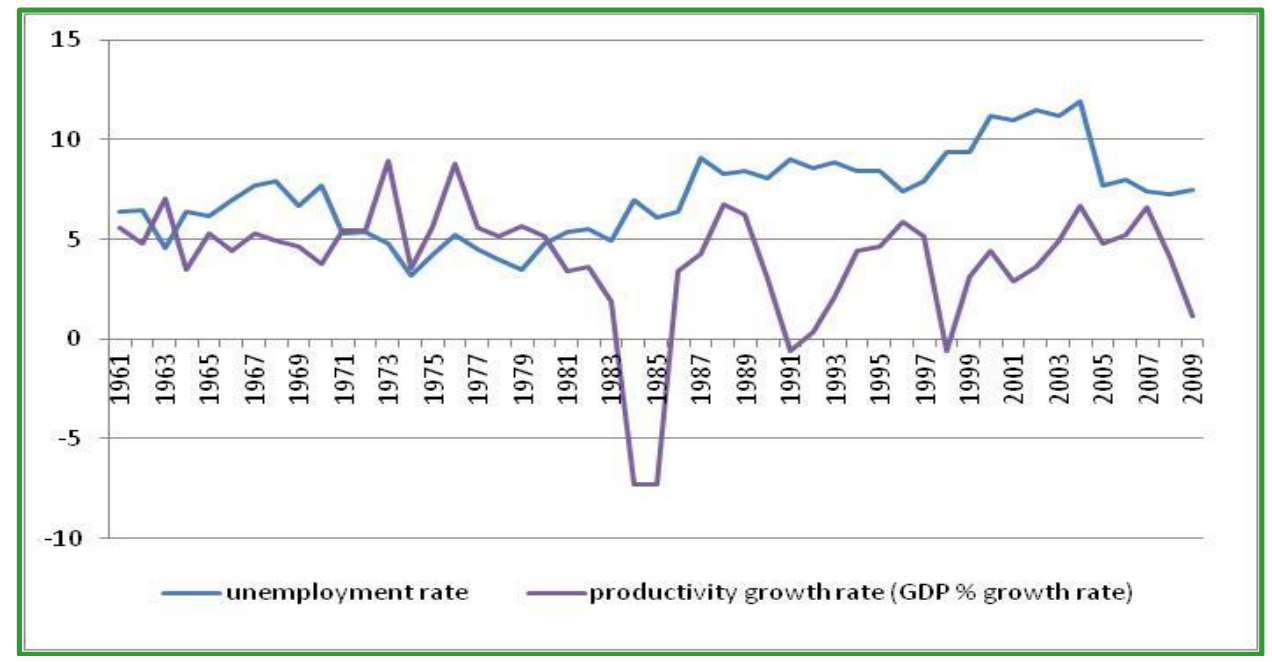

Figure-2. Unemployment Rate and GDP Growth Rate from 1961 to 2009.

The mixed evidences of Okun's Law suggest that there are other factors influencing the level of unemployment. Another track pursued in understanding the forces behind unemployment revolves around the Phillip's Curve.

"The Phillips curve represents the relationship between the rate of inflation and the unemployment rate. Although he had precursors, A. W. H. Phillips's study of wage inflation and unemployment in the United Kingdom from 1861 to 1957 provided evidence of a consistent inverse relationship: when unemployment was high, wages increased slowly; when unemployment was low, wages rose rapidly. Phillips conjectured that the lower the unemployment rate, the tighter the labor market and, therefore, the faster firms must raise wages to attract scarce labor. At higher rates of unemployment, the pressure abated. Phillips's "curve" represented the average relationship between unemployment and wage behavior over the business cycle. It showed the rate of wage inflation that would result if a particular level of unemployment persisted for some time"(Hoover, 2008). Most studies made use of the general price inflation rate as a proxy for wage inflation rate.

Using Engle-Granger two-step econometric procedure, Eita and Ashipala (2010) provided evidence that the Phillips curve holds for Namibia and unemployment such that there is a negative relationship between unemployment and inflation which can be reduced by increasing aggregate demand. In Romania, it was found that in the long run of 20 years there is no stable, statistically significant relationship between inflation and unemployment (Herman, 2010) and that inflation rate, along with seasonally adjusted net export and monetary policy rate, have a significant influence on the seasonally adjusted logarithmic value of the unemployment rate; the 
positive and negative signs of the independent variables are those expected: the net export and the monetary policy rates increase the value of the unemployment rate, whereas the cumulated seasonally adjusted inflation rate is in correlation with economic growth, therefore decreases unemployment rate (Kovács et al., 2010). Meanwhile, there is a non-proportional negative relationship between inflation and unemployment in a developing country like Pakistan using data from 1975-2009. There is a long-run and casual relationship between inflation and unemployment over the above mentioned period such that there is a transitory relationship (shocks) in the short-run, while there is a permanent relationship (shocks) in the long-run (Zaman et al., 2011). In the Philippines, regression results demonstrate a fairly robust Phillips curve relationship using Philippine data (Bagsic, 2004; Puzon, 2009).

\section{ECONOMETRIC METHODOLOGY}

To serve the purpose of this study, regression analysis, particularly the ordinary least squares procedure, was used. Considering that the data involved is a time series, a unit root test was initially conducted to test for stationarity of data.

\subsection{Model Specification}

Based on extant literature and the objectives of this study, the regression model is thus specified as follows:

$$
\begin{aligned}
\text { UNEMP }= & f(I N F, \text { GROWTH,AGEDEP }) \\
\text { UNEMP } P_{t}= & \beta_{0}+\beta_{1} I N F_{t}+\beta_{2} I N F_{t-1}+\beta_{3} G R O W T H_{t}+\beta_{4} I A G E D E P N F_{t} \\
& +\beta_{5} U N E M P_{t-1}+\varepsilon_{t}
\end{aligned}
$$

where,

$$
\begin{aligned}
& \text { UNEMP = Unemployment rate } \\
& \begin{array}{ll}
I N F & =\text { Inflation rate } \\
\text { GROWTH } & =\text { Annual change in real GDP as a proxy for economic growth } \\
\text { AGEDEP } & =\text { Age dependency ratio }
\end{array}
\end{aligned}
$$

It must be noted that following the procedure of Puzon (2009) who used the augmented version of Stiglitz's model to capture inflationary expectations, a first order lag of inflation rate was included in the model as a measure of the expected inflation rate. Furthermore, an unemployment lag of the first order was also included to determine if it could facilitate a better fit of the model as employed by Puzon (2009) as well. The age dependency ratio, the percentage of dependents - people younger than 15 or older than 64 - to the working age population - those ages 15-64, is included in the model based on the premise that the higher the number of dependents relative to the working age population may prompt the latter to actively seek employment and therefore lowers the unemployment rate.

The following are the hypotheses for the signs of the explanatory variables:

(a) Inflation, as stated by the Phillips Curve, is negatively related to unemployment. That is, if the demand for labor increases due to an expansionary monetary expansion, the 
unemployment rate would fall causing wages/prices to rise. Thus, creating la trade-off between inflation and unemployment.

(b) The unemployment lag is positively related t unemployment since the unemployed will increase the likelihood of the current unemployment rate unless they are able to find a job.

(c) Based on Okun's Law, one would expect the Okun's coefficient to be negative, such that rapid output growth is associated with a falling unemployment rate, and slow or negative output growth is associated with a rising unemployment rate (Knotek, 2007).

(d) The negative sign for the age dependency ratio is based on the premise that the higher the number of dependents become relative to the working age population, the latter is prompted to more actively seek employment to support the dependents and therefore is likely to result to a decrease in the unemployment rate.

\subsection{Data Description and Sources}

A total of 30 observations were used in the analysis. Inflation, annual percentage change of real GDP, unemployment rate, and age dependency ratio were all taken from the World Bank database. Inflation rate as measured by the consumer price index represents the annual percentage change in the cost to the average consumer of acquiring a basket of goods and services that may be fixed or changed at specified intervals, such as yearly. Data on annual percentage growth rate of GDP are expressed at market prices based on constant local currency. Aggregates are based on constant 2000 U.S. dollars. GDP is the sum of gross value added by all resident producers in the economy plus any product taxes and minus any subsidies not included in the value of the products and is calculated without making deductions for depreciation of fabricated assets or for depletion and degradation of natural resources. Unemployment refers to the share of the labor force that is without work but available for and seeking employment. The age dependency ratio represents the percentage of dependents - people younger that are 15 or older than 64 - to the working - age population - those ages 15-64 and are expressed as the proportion of dependents per 100 working-age population.

\subsection{Estimation Technique}

\subsubsection{Unit Root Test}

In dealing with time series data, it is a widely accepted procedure to first test the data for stationarity. The time series data are often non - stationary or have means, variances, and covariances that change over time. Non - stationary data are therefore unpredictable and henceforth provides little reliability as a source for forecasting or modeling (Iordanova, 2007). Hence, the time series data used in the study was subjected to unit root test to determine if it is stationary or not.

There are several procedures developed for this purpose. The Augmented Dickey - Fuller (ADF) test was employed in this study. It relies on rejecting a null hypothesis of unit root - that is, the series are non-stationary - in favor of the alternative hypotheses of stationarity. The tests 
are conducted with and without a deterministic trend $(t)$ for each of the series. The GRETL software form of ADF test is estimated by the following regression:

$$
(1-L) y_{t}=\beta_{0}+(\alpha-1) y_{t-1}+\alpha_{1}+e_{t}
$$

The coefficient $\beta_{0}$ is included when the series is assessed to have a trend, $(\alpha-1)=\gamma$ is the coefficient of interest in the Dickey - Fuller regression, and $\alpha_{1}$ is the term that 'augments' the Dickey - Fuller regression. It is included to eliminate autocorrelation in the model's errors, $e_{t}$, and more lags can be included if needed to accomplish this. The notation on the left side of the equation $(1-L) y_{t}$ makes use of the lag operator, $L$. The lag operator performs the $L y_{t}=y_{t-1}$. Thus, $(1-L) y_{t}=y_{t}-L y_{t}=y_{t}-y_{t-1}=\Delta y_{t}$.

If a series is found to be non-stationary at their levels but are stationary at their first difference, the said series is said to be integrated of order 1 usually denoted as I(1). Two nonstationary series are con-integrated if they tend to move together through time. Economic theory would suggest that they should be tied together via arbitrage, but that is no guarantee. Hence, such instance would prompt a test for co-integration to test substitutability of these assets using such methods as the Engle - Granger co-integration test or the Johansen test.

\subsubsection{Ordinary Least Squares (OLS) Regression Analysis}

After testing for stationarity and, as necessary, co-integration, we test for the relationship between unemployment, economic growth, inflation, and age dependency ratio using OLS, the model of which is as earlier specified. This procedure will reveal the existence, nature, strength, direction, and magnitude of possible predictive relationships.

It must be noted that modeling using OLS requires certain assumptions to hold true, one of which is for the error term to have a constant variance - that is, no heteroskedasticity - to obtain the best linear unbiased estimator (BLUE). Considering that generally, economic theory rarely gives any reason to believe that the errors are homoscedastic (Stock and Watson, 2009), the heteroskedasticity - robust standard errors were employed in applying the ordinary least squares linear regression to increase the efficiency of the OLS estimator - that is, a more valid statistical inference is possible.

\subsubsection{Test for Heteroskedasticity, Collinearity, and Serial Correlation}

To ensure that the OLS assumption of homoscedasticity is met, the initial model using the homoscedasticity - only variance formula was subjected to the White's test to test for heteroskedasticity. Once heteroskedasticity was established, regression was repeated using heteroskedasticity - robust standard errors.

Meanwhile, the presence of multicollinearity among independent variables prevents the isolation of the effects of one variable to the dependent variable which means that one or more regression coefficients could be estimated imprecisely. To ascertain that no such relationship exist among the independent variables, the variance inflation factor (VIF) was used to test for collinearity. The Durbin - Watson statistic was used to detect serial correlation. 


\section{EMPIRICAL FINDINGS}

\subsection{Unit Root Test}

This involves testing for the stationarity of the individual variables using the Augmented Dickey - Fuller (ADF) test to ascertain the existence of a unit root in each of the time series. The results of the ADF tests are shown in Table 1 . ADF test results show that the series involved are all stationary and is therefore suitable to be used for linear regression modeling and forecasting.

Table-1. Augmented Dickey - Fuller test results.

\begin{tabular}{|c|c|c|c|c|c|c|}
\hline \multirow[t]{2}{*}{ Variable } & \multicolumn{2}{|l|}{ With Constant } & \multicolumn{2}{|c|}{ With Constant \& Trend } & \multicolumn{2}{|c|}{$\begin{array}{l}\text { With Constant } \& \\
\text { Quadratic Trend }\end{array}$} \\
\hline & $\alpha-1$ & $\mathrm{t}$ & $\alpha-1$ & $\mathrm{t}$ & $\alpha-1$ & $\mathrm{t}$ \\
\hline UNEMP & -0.839104 & 0.08154 & -1.05204 & 0.1594 & $-1.43761^{* * *}$ & 0.02803 \\
\hline$I N F$ & $-0.565856^{* *}$ & 0.0424 & -0.767217 & 0.886 & -3.42486 & 0.564892 \\
\hline GROWTH & -0.660669 & 0.2444 & $-1.66782^{* * * *}$ & 0.008701 & $-2.1242 * * *$ & 0.001694 \\
\hline$A G E D E P$ & $-0.00130587 * *$ & 0.04983 & $-0.39941 * * *$ & 0.001262 & -0.7619 & 0.9007 \\
\hline
\end{tabular}

** Significant at $\alpha=0.05$.

If $\mathrm{p}<0.05$, the null hypothesis of non-stationarity is rejected - that is, the series is stationary. Coefficients were computed using GRETL.

Given this unit root test result, there was no need to test for co-integration. Henceforth, OLS was carried out.

\subsection{OLS Linear Regression Estimates}

Subjecting the data to OLS linear regression initially using homoscedasticity - only variance formula, the following linear regression estimate model is drawn based on the resulting coefficients presented in Table 2 .

Table-2. Model 1 coefficients using homoscedasticity - only variance formula.

\begin{tabular}{|c|c|c|c|c|c|}
\hline \multirow[t]{2}{*}{ Variables } & \multicolumn{2}{|c|}{ Unstandardized Coefficients } & \multirow{2}{*}{$\begin{array}{l}\text { Standardized } \\
\text { Coefficients } \\
\beta \beta\end{array}$} & \multirow{2}{*}{$t$} & \multirow{2}{*}{$p$-value } \\
\hline & $\widehat{\boldsymbol{\beta}}$ & Std. Error & & & \\
\hline$\alpha$ & 1.995 & 3.902 & & 0.501 & 0.621 \\
\hline$I N F_{t}$ & -0.049 & 0.039 & -0.247 & -1.255 & 0.222 \\
\hline$I N F_{t-1}$ & $-0.091 * *$ & 0.033 & -0.458 & -2.772 & 0.011 \\
\hline$U N E M P_{t-1}$ & $0.735^{* * * *}$ & 0.136 & 0.779 & 5.420 & 0.000 \\
\hline $\mathrm{GROWTH}_{t}$ & $-0.246^{*}$ & 0.118 & -0.468 & -2.079 & 0.049 \\
\hline$A G E D E P$ & 0.032 & 0.045 & 0.112 & 0.706 & 0.487 \\
\hline
\end{tabular}

*Significant at $\alpha=0.05$

**Significant at $\alpha=0.01$

****ignificant at $\alpha=0.001$

Coefficients were computed using SPSS

The summary and ANOVA results of Model 1 is presented in Table 3 and 4. 
Table-3. Model 1 summary

\begin{tabular}{l|l|l|l|l}
\hline $\boldsymbol{R}$ & $\boldsymbol{R}^{\mathbf{2}}$ & Adjusted $\boldsymbol{R}^{\mathbf{2}}$ & $\begin{array}{l}\text { Standard Error of the } \\
\text { Estimate }\end{array}$ & Durbin - Watson \\
\hline 0.853 & 0.727 & 0.667 & 1.0520 & 2.516 \\
\hline
\end{tabular}

Table-4. ANOVA results of Model 1.

\begin{tabular}{l|l|l|l|l|l}
\hline Model & $\begin{array}{l}\text { Sum of } \\
\text { Squares }\end{array}$ & df & Mean Square & F & $p$ - value \\
\hline Regression & 67.735 & 5 & 13.547 & $12.242^{* * * *}$ & 0.000 \\
\hline Residual & 25.452 & 23 & 1.107 & & \\
\hline Total & 93.188 & 28 & & \\
\hline *Significant at $\alpha=0.05$ & **** Significant at $\alpha=0.01$ &
\end{tabular}

Model 1 is correspondingly expressed in equation form as follows:

Model 1

$$
\begin{aligned}
& \widehat{U N E M P}_{t}=1.955-0.049 I N F_{t}-0.091 I N F_{t-1}-0.246 G R O W T H_{t}+ \\
& \text { (0.501) (-1.255) (-2.772)* } \quad(-2.079)^{*} \\
& 0.032 A G E D E P_{t}+0.735 U N E M P_{t-1} \\
& \text { (0.706) } \quad(5.420) * * * * \\
& r^{2}=0.727 \quad \mathrm{~F}=12.242 \quad p=0.000
\end{aligned}
$$

In this model (1), significant relationships were found to exist between unemployment and the first order lag of inflation, economic growth, and the first order lag of unemployment.

Using the White's test to test for this model's heteroskedasticity, the $\mathrm{p}$ - values of each variable's statistics are greater than $\alpha=0.05$. Hence, the null hypothesis that the model is homoscedastic is rejected. This illustrates the heteroskedasticity of most economic realities.

\begin{tabular}{|c|c|c|c|c|}
\hline \multirow{2}{*}{ Variables } & \multicolumn{2}{|c|}{ Unstandardized Coefficients } & \multirow{2}{*}{$t$} & \multirow{2}{*}{$p$ - value } \\
\hline & $\widehat{\boldsymbol{\beta}}$ & Std. Error & & \\
\hline $\mathrm{A}$ & 1.99543 & 2.31764 & 0.8437 & 0.4075 \\
\hline$I N F_{t}$ & -0.0492815 & 0.0310308 & -1.588 & 0.1259 \\
\hline$I N F_{t-1}$ & $-0.0906512^{* * *}$ & 0.0187705 & -4.829 & 0.0000 \\
\hline$U N E M P_{t-1}$ & $0.7350550^{* * *}$ & 0.130523 & 5.632 & 0.0000 \\
\hline $\mathrm{GROWTH}_{t}$ & $-0.245577^{* * *} *$ & 0.0654481 & -3.752 & 0.0010 \\
\hline$A G E D E P$ & 0.0320663 & 0.0321026 & 0.9989 & 0.3283 \\
\hline
\end{tabular}

Consequently, OLS regression using heteroskedasticity - robust standard errors was run on the same variable series, the results of which are shown in Table 5. This procedure yielded the following linear regression estimates:

Table-5. Model 2 coefficients using heteroskedasticity - robust standard errors. 
Table-6. Model 2 summary.

\begin{tabular}{l|l|l|l}
\hline Sum squared resid & $\mathbf{2 5 . 4 5 2 4 7}$ & S.E. of regression & $\mathbf{1 . 0 5 1 9 6 5}$ \\
\hline R-squared & 0.726868 & Adjusted R-squared & 0.667492 \\
\hline $\mathrm{F}(5,23)$ & $50.37016^{* * * *}$ & P-value $(\mathrm{F})$ & $1.24 \mathrm{e}-11$ \\
\hline Log-likelihood & -39.25722 & Akaike criterion & 90.51443 \\
\hline Schwarz criterion & 98.71821 & Hannan-Quinn & 93.08375 \\
\hline Rho & -0.271153 & Durbin's $\mathrm{h}$ & -1.984032 \\
\hline *Significant at $\alpha=0.05 \quad$ **ignificant at $\alpha=0.01$ & $* *$ Significant at $\alpha=0.001$ \\
Coefficients were computed using GRETL.
\end{tabular}

The summary of Model 2 is presented in Table 6.

Correspondingly, Model 2 is expressed in equation form as:

\section{Model 2}

$$
\begin{gathered}
U \widehat{N E M} P_{t}=1.955-0.049 I N F_{t}-0.091 I N F_{t-1}-0.246 G R O W T H_{t}+ \\
(0.8437) \quad\left(-1.588 \quad(-4.829)^{* * * *} \quad(-3.752)^{* * * *}\right. \\
(0.9989) \quad 0.032 A G E D E P_{t}+0.735 U N E M P_{t-1} \\
(5.632)^{* * * *}
\end{gathered}
$$$$
r^{2}=0.727 \quad \mathrm{~F}=50.370 \quad p=0.000
$$

Model 2 shows that the negative relationship between unemployment and inflation as postulated by the Phillips Curve is true for the Philippines. For a one percent increase in inflation rate, unemployment decreases by approximately $4.93 \%$, consequently supporting the premise on the trade-off between inflation and unemployment as espoused by the Phillips Curve. However, the unemployment - inflation relationship is not statistically significant. This confirms the result of the study of Puzon (2009) which yielded a similar direction in the relationship and that of Bagsic (2004) albeit another econometric approach and significance parameters were used. These results suggest that if an expansionary monetary policy results to increasing inflation rates, the unemployment rate would drop. This could be due to increased attempts to cope with rising cost of living that is caused by inflation. Puzon (2009) explains that if the demand for labor increased due to an expansionary monetary policy, the unemployment rate would fall. Then, wages and consumer prices will tend to rise.

The first order lag of inflation was also found to be negatively related with unemployment at a significance level of $\alpha=0.001$. This implies that the traces of the effects of the prior year's inflation rate could still be felt in terms of unemployment rate such that for every $1 \%$ increase in the inflation rate immediately a year prior to the current year, unemployment may decrease by about $9.1 \%$.

Furthermore, the unemployment lag obtained a highly significant positive relationship with current unemployment. Though this may be suggestive of a lag in the outcomes of fiscal policies addressing unemployment issue and slow expansion of private businesses that could have generated employment, this result also imply that holding other factors constant, unemployment perennially multiplies at about $73.5 \%$ year on year. Puzon (2009) posits that the significance of the unemployment lag could indicate that fiscal policies relating to inflation might not have an 
immediate effect; and that there could be policy lags. This highlights the impetus of urgently addressing the unemployment problem to slow down, if not curb, its increase.

On the other hand, results of the study indicate that the negative relationship between unemployment and economic growth as theorized by the Okun's Law significantly holds true for the Philippines. For a one percent increase in economic growth rate, unemployment rate decreases by $24.56 \%$.

Finally, findings indicate a positive relationship between age dependency ratio and unemployment rate although the relationship is not statistically significant. It is possible that the incremental increases in birth rates exceeds the incremental increases in the employment rate ka connection that is worthy of further investigation as this may have implications on labor and population control policies.

The adjusted $r^{2}$ of $66.75 \%$ coupled with a highly significant $\mathrm{F}$ - statistics of 50.370 indicates that the model assumes a relatively good fit (Table 6 ). The $r^{2}$ of $72.69 \%$ denotes that only $27.31 \%$ of the variation in unemployment cannot be explained by a variation in any of the variables in the model.

The test for collinearity using the Variance Inflation Factor (VIF) coefficient indicates that none of the variables are correlated with each other hence, the issue on multicollinearity is dismissed.

\section{CONCLUSION}

The objective of this study is to determine whether there exist a relationship between economic growth, inflation, and age dependency ratio to unemployment in the Philippines. Widely recognized theories have posited that these macroeconomic indicators are related and some facets of these relationships have been investigated in the Philippine setting. However, the inclusion of age dependency ratio contributes to the novelty of the model studied.

Regression results confirm Okun's Law in the Philippines - that is, economic growth is negatively influence unemployment. However, Knotek (2007) cautions that although Okun's Law predicts the relationship between changes in the unemployment rate and economic growth, there have been historical instances when this has not been the case such as during recessions and expansions. Hence, the law must be regarded only as a rule of thumb and not as a "structural feature" of the economy.

Meanwhile, the results of the study also confirmed Phillips Curve in the Philippines - that is, inflation negatively influences unemployment, albeit, not statistically significant.

However, the first order lag of inflation proved to be significantly related with unemployment. The Phillips Curve depicts the tradeoff between inflation and unemployment rate. Studies have shown its usefulness in policymaking and most importantly, in forecasting inflation Bagsic (2004). The belief that monetary policy has employment effects is inextricably tied to the belief in the inflation - unemployment tradeoff (Ball and Mankiw, 2002). They further explained that labor market conditions (through wage) affect consumer price inflation, while monetary policy can affect unemployment rate via the inflation channel. It is only through this channel that monetary policy affects unemployment rate. Meanwhile, Ball and Mankiw (2002) further assert 
that fiscal policy tools to affect unemployment rate abound. Thus, it is deemed desirable to actively seek a better understanding of the relationship between inflation and unemployment rate on the part of the policymakers and analysts for better coordination of fiscal and monetary policies. It has been widely acknowledged among economists that knowledge of what level of unemployment rate will trigger high inflation which can then, in turn, be harmful to the investment climate is desirable to both policymakers and capital investors. Thus, this relationship is more than academic interest and can be useful to investors in forecasting future inflation.

On the other hand, age dependency ratio was found to be positively related with unemployment. Furthermore, there was a statistically significant positive relationship between unemployment and its first order lag. The positive relationship of the employment lag calls for more urgent and drastic fiscal and monetary policies that address this concern.

Overall, the model proved to provide a relatively good fit of the data as indicated by its coefficient of determination.

\section{REFERENCES}

Bagsic, C.B., 2004. The phillips curve and inflation forecasting: The case of the Philippines. Philippine Management Review, (11): 76-90.

Ball, L. and N.G. Mankiw, 2002. The NAIRU in theory and practice. Journal of Economic Perspectives, 16(4): 115-136.

Bautista, G.M., 2003. An assessment of the Philippine economy. Review Essay. Available from http://kyotoreview.cseas.kyoto-u.ac.jp/issue/issue3/article_277.html [Accessed October 13, $2011]$.

De La Paz, D., 2009. Okun's law. Filipino voices. Available from http://filipinovoices.com/okun\%E2\%80\%99s-law [Accessed October 13, 2011 ].

Eita, J.H. and J.M. Ashipala, 2010. Determinants of unemployment in Namibia. International Journal of Business and Management, 5(10): 92-104.

Herman, E., 2010. Inflation and unemployment in the Romanian economy. Annals of the University of Petroşani, Economics, 10(2): 157-179.

Hoover, K.D., 2008. The concise encyclopedia of economics: Phillips curve. Library of Economics and Liberty. Available from http://www.econlib.org/library/Enc/PhillipsCurve.html [Accessed October 13,2011].

Ide, J., S.J. Peiris and A. Tuladhar, 2011. IMF country report, Philippines: Selected issues paper. International monetary fund. Asia and pacific department. Washington, D.C: International Monetary Fund.

ILO, 2011. Employment and unemployment. Internationl Labor Organization. Available from http://www.ilo.org/global/statistics-and-databases/statistics-overview-and-topics/employmentand-unemployment/lang--en/index.htm [Accessed October 13, 2011$].$

IMF, 2009. Special data dissemination standard: Slovak republic summary methodology labor market: Unemployment. International Monetary Fund. Available from http://dsbb.imf.org/pages/sdds/BaseSMReport.aspx?ctycode=SVK\&catcode=UEMoo\&ctyType =SDDS [Accessed October 13, 2011 ]. 
International Monetary Fund, 2011. Philippines: Selected issues paper. IMF Country Report, 11(58): 1-38.

Investopedia, 2011. Dictionary: Okun's law. Investopedia. Available from http://www.investopedia.com/terms/o/okunslaw.asp\#axzz1aczhFJUZ [Accessed October 13, $2011]$.

Iordanova, T., 2007. Introduction to stationary and non-stationary processes. Investopedia. Available from http://www.investopedia.com/articles/trading/07/stationary.asp\#axzz1aczhFJUZ [Accessed October 14, 2011].

Knotek, E.I., 2007. How useful is Okun's law?. Economic Review, (Q IV): 73-103.

Kovács, I., N. Marton, K. Patka and K. Páll, 2010. The determinants of the unemployment rate - empirical evidence from Romania. Annals of the University of Oradea: Economic Science, 1(2): 277-282.

Kreishan, F.M., 2010. Economic growth and unemployment: An empirical analysis. Journal of Social Sciences, 7(2): 228-231.

Puzon, K.A., 2009. The inflation dynamics of the ASEAN-4: A case study of the phillips curve relationship. Report and Opinion, 1(2): 42-44.

Rafiq, M., I. Ahmad, A. Ullah and Z. Khan, 2010. Determinants of unemployment: A case study of Pakistan economy (1998 - 2008). Abasyn Journal of Social Sciences, 3(1): 17-24.

Stock, J.H. and M.W. Watson, 2009. Introduction to econometrics (Brief). Jurong, Singapore: Pearson Education South Asia Pte Ltd.

Tatoglu, F.Y., 2011. The long and short run effects between unemployment and economic growth in Europe. Doğuş Üniversitesi Dergisi, 12(1): 99-113.

Zaman, K., M.M. Khan, M. Ahmad and W. Ikram, 2011. Inflation, unemployment and the NAIRU in Pakistan (1975-2009). International Journal of Economics and Finance, 3(1): 245-254. 